ARD

ONLINE

\title{
Associations of obesity with modifiable risk factors for the development of cardiovascular disease in patients with rheumatoid arthritis
}

Antonios Stavropoulos-Kalinoglou, Giorgos S Metsios, Vasileios F Panoulas, Karen M J Douglas, Alan M Nevill, Athanasios Z Jamurtas, Marina Kita, Yiannis Koutedakis and George D Kitas

Ann Rheum Dis published online 3 Aug 2008;

doi:10.1136/ard.2008.095596

Updated information and services can be found at:

http://ard.bmj.com/cgi/content/abstract/ard.2008.095596v1

These include:

Rapid responses You can respond to this article at:

http://ard.bmj.com/cgi/eletter-submit/ard.2008.095596v1

Email alerting Receive free email alerts when new articles cite this article - sign up in the box at the service top right corner of the article

Notes

Online First contains unedited articles in manuscript form that have been peer reviewed and accepted for publication but have not yet appeared in the paper journal (edited, typeset versions may be posted when available prior to final publication). Online First articles are citable and establish publication priority; they are indexed by PubMed from initial publication. Citations to Online First articles must include the digital object identifier (DOIs) and date of initial publication.

To order reprints of this article go to:

http://journals.bmj.com/cgi/reprintform

To subscribe to Annals of the Rheumatic Diseases go to:

http://journals.bmj.com/subscriptions/ 
Associations of obesity with modifiable risk factors for the development of cardiovascular disease in patients with rheumatoid arthritis

Antonios Stavropoulos-Kalinoglou ${ }^{1,2,3}$, Giorgos S. Metsios ${ }^{1,2,3}$, Vasileios F. Panoulas ${ }^{3}$, Karen M.J. Douglas $^{3}$, Alan M. Nevill ${ }^{1,2}$, Athanasios Z. Jamurtas ${ }^{4,5}$, Marina Kita ${ }^{3}$, Yiannis Koutedakis ${ }^{1,4,5}$, George D. Kitas ${ }^{2,3,6}$

${ }^{1}$ School of Sport, Performing Arts \& Leisure, Wolverhampton University, Gorway Road, Walsall, WS1 3BD, West Midlands, UK.

${ }^{2}$ Research Institute in Healthcare Science, University of Wolverhampton, Wulfruna Street, Wolverhampton, WV1 1LY, West Midlands, UK.

${ }^{3}$ Department of Rheumatology, Dudley Group of Hospitals NHS Trust, Russell's Hall Hospital, Pensnett Road, Dudley, DY1 2HQ, West Midlands, UK.

${ }^{4}$ Department of Sport and Exercise Science, University of Thessaly, Trikala-Karyes Road, Trikala, 42100, Greece.

${ }^{5}$ Institute of Human Performance \& Rehabilitation, Trikala-Karyes Road, Trikala, 42100, Greece.

${ }^{6}$ ARC Epidemiology Unit, University of Manchester, Oxford Road, Manchester, M13 9PT, UK

Author for Correspondence:

Antonios Stavropoulos-Kalinoglou

Department of Rheumatology, Russells Hall Hospital

Dudley Group of Hospitals NHS Trust

Dudley, West Midlands, DY1 2HQ, UK

e-mail: $\underline{\text { as@wlv.ac.uk }}$

Word Count

Abstract: 185

Main text: 1490

References: 15

Tables: 1

Figures: 2 


\begin{abstract}
Objectives: To assess the associations of body mass index (BMI) with modifiable cardiovascular disease (CVD) risk factors in patients with rheumatoid arthritis (RA)

Methods: BMI, disease activity, selected CVD risk factors and CVD medication were assessed in 378 (276 females) RA patients. Patients exceeding accepted thresholds in $\geq 3$ CVD risk factors were classified as having the metabolic syndrome (MetS).

Results: BMI independently associated with hypertension ( $\mathrm{OR}=1.28 \quad(95 \% \mathrm{CI}=1.22-1.34)$; $\mathrm{p}=0.001)$, HDL $(\mathrm{OR}=1.10(1.06-1.15) ; \mathrm{p}=0.025)$, insulin resistance $(\mathrm{OR}=1.13(1.08-1.18)$; $\mathrm{p}=0.000)$ and the MetS $(\mathrm{OR}=1.15$ (1.08-1.21); $\mathrm{p}=0.000)$. In multivariable analyses, BMI had the strongest associations with CVD risk factors $\left(\mathrm{F}_{1-354}=8.663, \mathrm{p}=0.000\right)$, and was followed by lipidlowering treatment $\left(\mathrm{F}_{1-354}=7.651, \mathrm{p}=0.000\right)$, age $\left(\mathrm{F}_{1-354}=7.541, \mathrm{p}=0.000\right)$, antihypertensive treatment $\left(\mathrm{F}_{1-354}=4.997, \mathrm{p}=0.000\right)$ and gender $\left(\mathrm{F}_{1-354}=4.707, \mathrm{p}=0.000\right)$. Prevalence of hypertension $(\mathrm{p}=0.004)$, insulin resistance $(\mathrm{p}=0.005)$ and the MetS $(\mathrm{p}=0.000)$ was significantly different between normal, overweight and obese RA patients, and BMI differed significantly according to the number of risk factors present $(\mathrm{p}=0.000)$.

Conclusions: Increasing BMI associates with increased CVD risk independently of many confounders. RA-specific BMI cut-off points better identify RA patients at increased CVD risk. Weight-loss regimes should be developed and applied in order to reduce CVD in RA patients.
\end{abstract}

Key words: body mass index, obesity, cardiovascular disease, metabolic syndrome, weight loss 


\section{INTRODUCTION}

Rheumatoid arthritis (RA) associates with increased risk for cardiovascular disease (CVD) [1]. This is most likely a combination of genetic predisposition [2], modifiable CVD risk factors and the inflammatory burden of the disease [3]. RA patients have significantly higher body fat content compared to healthy individuals of the same height and weight [4]. This led to the development of RA-specific body mass index (BMI) thresholds for overweight and obesity that better identify RA patients with increased body fat [4], and possibly CVD risk.

In the general population, obesity is a major contributor to dyslipidaemia, hypertension, and insulin resistance [5] and the underlying cause of the metabolic syndrome (MetS) [5]. The associations between obesity and CVD risk factors or the MetS in RA have not been extensively investigated. Obesity in this population is usually considered a confounder, against which data should be standardised, but not as the possible underlying cause for several CVD risk factors. The aim of this study was to quantify the associations of BMI with classical CVD risk factors in a large sample of RA patients.

\section{MeThODS}

\section{Participants}

The study had ethical approval and all volunteers provided informed consent. A total of 400 (289 female) consecutive RA patients were assessed. Of them none had uncontrolled thyroid disease, but 22 were excluded due to cancer. The analyses from the remaining 378 (276 female) patients are reported: their characteristics appear in Table 1.

Table 1: Demographic and disease characteristics of volunteers [median (interquartile range)]

\begin{tabular}{|l|l|l|}
\hline & MALE & FEMALE \\
\hline $\mathrm{N}$ & 102 & 276 \\
Age & $63.5(13.6)$ & $63(14.8)$ \\
Height & $173.0(9.8)$ & $160.0(8.0)$ \\
Weight & $83.3(19.7)$ & $70.0(19.9)$ \\
BMI & $27.6(5.5)$ & $26.7(7.2)$ \\
DAS28 & $4.0(1.8)$ & $4.2(1.9)$ \\
HAQ & $1.2(1.8)$ & $1.6(1.5)$ \\
ESR & $19.0(30.0)$ & $21.0(28.0)$ \\
CRP & $10.0(15.0)$ & $8.0(13.0)$ \\
Disease Duration & $9.0(15.0)$ & $10.0(15.0)$ \\
\hline
\end{tabular}

\section{Assessments}

Standing height, weight, BMI $\left(\mathrm{kg} / \mathrm{m}^{2}\right)$ and waist circumference were measured. CVD risk factors (blood pressure [BP], lipids) were assessed, smoking status noted and the Framingham 10year CVD event probability was calculated. The Homeostasis Model Assessment of insulin resistance (HOMA) and the Quantitative Insulin sensitivity Check Index (QUICKI), were used to determine insulin resistance (IR). The NCEP ATP III criteria [5] were used to identify patients with the MetS. Erythrocyte sedimentation rate (ESR), C-reactive protein (CRP), Disease Activity Score-28 (DAS28), and the Stanford Health Assessment Questionnaire (HAQ) were also assessed. 
$\underline{\text { Data Analysis }}$

The Statistical Package for Social Sciences version 15.0 was used (SPSS Inc. Chicago, IL, USA). Dispersion of the variables was assessed using the Kolmogorov-Smirnov test. Spearman's correlations explored the associations of CVD risk factors and 10-year CVD event probability with BMI. Results were standardised for gender, age, smoking status, RA characteristics and CVD medication using univariable analyses. Multivariable analyses were used to asses the overall association of each of the possible confounders with the CVD risk factors and the 10-year CVD event probability.

Following grouping according to RA-specific BMI [4] in underweight, normal-weight, overweight and obese, analysis of Variance (ANOVA) was used to assess differences in BP, lipids and IR between groups. Analysis of Co-Variance (ANCOVA) was then used to standardise for the same possible confounders as above. Chi-squared analyses were used to identify differences in the prevalence of each risk factor or the MetS between BMI groups. Binary logistic models were used to test the independence of these associations from the same possible confounders.

Finally, patients were grouped according to the total number of risk factors they had. ANOVA was used to assess differences in BMI among these latter groups and ANCOVA to adjust for the same possible confounders. Data are reported as median (interquartile range). Statistical significance was set to $\mathrm{p}<0.05$.

\section{RESULTS \\ BMI and CVD risk factors}

BMI correlated significantly with systolic BP $(r=0.240, p=0.000)$, HDL $(r=-183, p=0.000)$, HOMA $(\mathrm{r}=0.302, \mathrm{p}=0.000)$ and QUICKI $(\mathrm{r}=-0.300, \mathrm{p}=0.000)$. BMI also correlated with ESR $(\mathrm{r}=0.128, \mathrm{p}=0.011), \mathrm{CRP}(\mathrm{r}=0.155, \mathrm{p}=0.002)$ and HAQ $(\mathrm{r}=0.133, \mathrm{p}=0.009)$, therefore results were standardised for these parameters as well as for gender, age, smoking, and CVD medication. BMI retained its association with systolic $\mathrm{BP}\left(\mathrm{F}_{1-354}=23,372, \mathrm{p}=0.000\right)$, HDL $\left(\mathrm{F}_{1-354}=10.439, \mathrm{p}=0.001\right)$, $\operatorname{HOMA}\left(\mathrm{F}_{1-354}=11.311, \mathrm{p}=0.001\right)$ and QUICKI $\left(\mathrm{F}_{1-354}=34.678, \mathrm{p}=0.000\right)$ and also associated with diastolic $\mathrm{BP}\left(\mathrm{F}_{1-354}=7,593, \mathrm{p}=0.006\right)$, triglycerides $\left(\mathrm{F}_{1-354}=4.496, \mathrm{p}=0.035\right)$ and 10-year $\mathrm{CVD}$ event probability $\left(\mathrm{F}_{1-354}=5.857, \mathrm{p}=0.016\right)$. Different multivariate models, using $\mathrm{BP}$, lipids and $\mathrm{IR}$ as dependent variables, gender and smoking status as factors and BMI, age, RA characteristics and CVD medication as covariates indicated that the variance observed in all CVD risk factors was more closely associated with $\mathrm{BMI}\left(\mathrm{F}_{1-354}=8.663, \mathrm{p}=0.000\right)$, followed by lipid-lowering treatment $\left(\mathrm{F}_{1-354}=7.651, \mathrm{p}=0.000\right)$, age $\left(\mathrm{F}_{1-354}=7.541, \mathrm{p}=0.000\right)$, antihypertensive treatment $\left(\mathrm{F}_{1-354}=4.997\right.$, $\mathrm{p}=0.000)$ and male gender $\left(\mathrm{F}_{1-354}=4.707, \mathrm{p}=0.000\right)$.

ANCOVA, with corrections for gender, age, smoking, RA characteristics and usage of CVD medication, showed significant differences between BMI sub-groups (underweight, normalweight, overweight and obese) for systolic $\mathrm{BP}\left(\mathrm{F}_{1-354}=14.707, \mathrm{p}=0.000\right)$, diastolic $\mathrm{BP}\left(\mathrm{F}_{1-354}=6.457\right.$, $\mathrm{p}=0.011)$, triglycerides $\left(\mathrm{F}_{1-354}=4.700, \mathrm{p}=0.031\right)$, HDL $\left(\mathrm{F}_{1-354}=7.545, \mathrm{p}=006\right)$, HOMA $\left(\mathrm{F}_{1-354}=9.720\right.$, $\mathrm{p}=0.002)$, QUICKI $\left(\mathrm{F}_{1-354}=30.332, \mathrm{p}=0.000\right)$ and 10 -year $\mathrm{CVD}$ event probability $\left(\mathrm{F}_{1-354}=3.981\right.$, $\mathrm{p}=0.046)$.

\section{BMI subgroups and the prevalence of CVD risk factors}

Cross-tabulation of BMI subgroups with presence or absence of each risk factor or the MetS demonstrated significant differences between groups for the prevalence of hypertension $(\mathrm{p}=0.004)$, insulin resistance $(\mathrm{p}=0.005)$ and the MetS $(\mathrm{p}=0.000)$ (Figure 1). The binary logistic models indicated that BMI associated with hypertension $(\mathrm{OR}=1.28,95 \% \mathrm{CI}=1.22-1.34 ; \mathrm{p}=0.001)$, 
HDL $(\mathrm{OR}=1.10,95 \% \mathrm{CI}: 1.06-1.15 ; \mathrm{p}=0.025)$, IR $(\mathrm{OR}=1.13,95 \% \mathrm{CI}=1.08-1.18 ; \mathrm{p}=0.000)$ and the MetS (OR=1.15, 95\% CI: 1.08-1.21; $\mathrm{p}=0.000)$ independently of confounding factors.

Following grouping for the total number of risk factors present, ANOVA showed significant differences in BMI between groups ( $\mathrm{p}=0.000$; Table 1), while ANCOVA revealed that this association was independent of gender, age, smoking, RA characteristics and usage of CVD medication $(\mathrm{p}=0.000)$.

\section{DISCUSSION}

These results suggest an almost linear relationship between BMI and CVD risk in this patient group, with the risk profile worsening as BMI increases, in a pattern similar to that described in the general population [5]. These associations were independent of multiple confounders, and if anything, they became stronger following inclusion of CVD medication in the models. It must be emphasised that these are all cross-sectional associations, and they do not provide definitive evidence for causality or directionality: longitudinal studies are required for this.

There is no reason to suggest that the mechanisms by which obesity increases CVD risk in RA are different from those in the general population. Excess adipose tissue releases nonesterified fatty acids in the circulation, which overload the liver and muscles with lipids and increase lipolysis, while reducing glucose utilization. Circulating glucose stimulates insulin production, leading to insulin resistance [6]. Endothelial function is often impaired causing arterial stiffness and hypertension [7]. Obesity may also increase CVD risk by reducing adiponectin, activating the rennin-angiotensin-aldosterone system, and increasing sympathetic activity and renal sodium reabsorption [6]. However as we did not measure any of these parameters we can only postulate about their contribution to our observations.

Recent studies in RA have shown no relation [8] or even a "paradoxical" protective effect of obesity against CVD [9], although no potential mechanisms were described. In our study, lipidlowering and anti-hypertensive drugs strongly associated with CVD risk factors; their inclusion in the models strengthened the association of BMI with all risk factors assessed. Such drugs, known to improve CVD risk and reduce mortality, are more frequently prescribed in obese than in nonobese individuals [10]. Thus their inclusion in the analyses of studies investigating CVD risk and outcome in RA is of paramount importance.

In the present study, neither disease characteristics nor smoking affected the associations of BMI with CVD risk. This finding is similar to our previous observations indicating that alterations in body composition of RA patients occur in the early years of the disease [4] or even prior to it. This could be the case for some CVD risk factors since "the risk of coronary heart disease in RA patients precedes the ACR criteria-based diagnosis of RA" [11]. Similarly, smoking appears to confer less CVD risk in RA than in the general population [3]. Most likely, this is a result of the smoking-induced weight-loss we recently described in RA [12] which may counteract the known negative effects of smoking on risk factors. However, disease characteristics and smoking were treated solely as possible confounders, thus their direct associations with CVD risk in RA cannot be assessed in this study.

An important finding of the present study is the BMI level at which CVD risk increases. Patients with one risk factor had a median BMI of $<25 \mathrm{~kg} / \mathrm{m}^{2}$ whereas those with the MetS $<30$ $\mathrm{kg} / \mathrm{m}^{2}$ and by applying general BMI thresholds would be classified as normal-weight and overweight respectively; however, based on RA-specific BMI thresholds they would be classified as over-weight or obese. This could be important in routine clinical practice, where such 
classifications may be used to target patients at increased risk for screening, early identification and management of risk factors.

In the general population, weight-loss can reverse the adverse effects of obesity. However, in a population with significant muscle wasting, such as RA, the type of weight-loss intervention has to be carefully considered. Among existing weight-loss regimes, exercise and especially resistance training, is the only one proven to increase muscle mass in the general population [13] and may be applied in RA patients without aggravating their disease [14]. Moreover, exercise is known to further reduce CVD risk irrespective of weight-loss [15]. Research focusing on weightloss interventions and their effects on CVD in RA are necessary.

Within its limitations, this study shows that increasing BMI in RA patients associates with increased CVD risk. The use of RA-specific BMI thresholds better identifies RA patients at increased CVD risk. Weight-loss regimes specific for RA patients need to be developed and evaluated. 


\section{LiST OF ABbREVIATIONS}

RA: Rheumatoid Arthritis

BMI: Body Mass Index

CVD: Cardiovascular Disease

HDL: High Density Lipoprotein

LDL: Low Density Lipoprotein

BP: Blood Pressure

IR: Insulin Resistance

HOMA: Homeostasis Model Assessment of Insulin Resistance

QUICKI: Quantitative Insulin sensitivity Check Index

MetS: Metabolic Syndrome

ESR: Erythrocyte Sedimentation Rate

CRP: C- Reactive Protein

DAS: Disease Activity Score 28

HAQ: Health Assessment Questionnaire

ANOVA: Analysis of Variance

ANCOVA: Analysis of Co-variance

\section{ACKNOWLEDGEMENTS}

This study was funded by the Dudley Group of Hospitals R\&D directorate cardiovascular programme grant and a Wolverhampton University equipment grant. The department of rheumatology has an infrastructure support grant from the Arthritis Research Campaign (number: 17682).

\section{COMPETING INTERESTS}

The authors have no competing interest to declare

\section{Authors' Consent to Publication}

The Corresponding Author has the right to grant on behalf of all authors and does grant on behalf of all authors, an exclusive licence (or non-exclusive for government employees) on a worldwide basis to the BMJ Publishing Group Ltd and its Licensees to permit this article (if accepted) to be published in Annals of the Rheumatic Diseases editions and any other BMJPGL products to exploit all subsidiary rights, as set out in our licence http://ard.bmjjournals.com/ifora/licence.pdf 


\section{FIGURE LEGENDS}

Figure 1: Mean (95\% confidence interval of the mean) for BMI of participants according to risk factor grouping.

Differences between groups in BMI are significant $(\mathrm{p}=0.000)$

Risk factors include: Hypertension, high triglycerides, low high-density-lipoprotein, insulin resistance, waist circumference

Figure 2: Prevalence of individual risk factors and the metabolic syndrome for each BMI group

Significant differences between BMI groups were found for the prevalence of hypertension $(\mathrm{p}=0.004)$, insulin resistance $(\mathrm{p}=0.005)$ and the metabolic syndrome $(\mathrm{p}=0.000)$. 


\section{REFERENCES}

1. Kitas GD, Erb N. Tackling ischaemic heart disease in rheumatoid arthritis. Rheumatology (Oxford) 2003;42:607-13.

2. Gonzalez-Gay MA, Gonzalez-Juanatey C, Lopez-Diaz MJ, Pineiro A, Garcia-Porrua C, MirandaFilloy JA, et al. HLA-DRB1 and persistent chronic inflammation contribute to cardiovascular events and cardiovascular mortality in patients with rheumatoid arthritis. Arthritis Rheum 2007;57:125-32.

3. Gonzalez A, Kremers HM, Crowson CS, Ballman KV, Roger VL, Jacobsen SJ, et al. Do cardiovascular risk factors confer the same risk for cardiovascular outcomes in rheumatoid arthritis patients as in non-rheumatoid arthritis patients? Ann Rheum Dis 2008;67:64-9.

4. Stavropoulos-Kalinoglou A, Metsios GS, Koutedakis Y, Nevill AM, Douglas KM, Jamurtas A, et al. Redefining overweight and obesity in rheumatoid arthritis patients. Ann Rheum Dis 2007;66:131621.

5. Grundy SM, Brewer HB, Jr, Cleeman JI, Smith SC, Jr, Lenfant C, for the Conference Participants. Definition of Metabolic Syndrome: Report of the National Heart, Lung, and Blood Institute/American Heart Association Conference on Scientific Issues Related to Definition. Circulation 2004;109:4338.

6. Bray GA, Bouchard C, James WPT. Handbook of obesity. New York: Marcel Dekker; 1998.

7. Zizek B, Poredos P, Videcnik V. Endothelial dysfunction in hypertensive patients and in normotensive offspring of subjects with essential hypertension. Heart 2001;85:215-7.

8. Naranjo A, Sokka T, Descalzo MA, Calvo-Alen J, Horslev-Petersen K, Luukkainen RK, et al. Cardiovascular disease in patients with rheumatoid arthritis: results from the QUEST-RA study. Arthritis Res Ther 2008;10:R30 [Epub ahead of print].

9. Escalante A, Haas RW, del Rincon I. Paradoxical effect of body mass index on survival in rheumatoid arthritis: role of comorbidity and systemic inflammation. Arch Intern Med. 2005;165:1624-9.

10. Karelis AD, St-Pierre DH, Conus F, Rabasa-Lhoret R, Poehlman ET. Metabolic and body composition factors in subgroups of obesity: what do we know? J Clin Endocrinol Metab 2004;89:2569-75.

11. Maradit-Kremers H, Crowson CS, Nicola PJ, Ballman KV, Roger VL, Jacobsen SJ, et al. Increased unrecognized coronary heart disease and sudden deaths in rheumatoid arthritis: A populationbased cohort study. Arthritis \& Rheumatism 2005;52:402-11.

12. Stavropoulos-Kalinoglou A, Metsios GS, Panoulas VF, Douglas KM, Nevill AM, Jamurtas AZ, et al. Cigarette smoking associates with body weight and muscle mass of patients with rheumatoid arthritis: a cross-sectional, observational study. Arthritis Res Ther 2008;10:R59.

13. Franz MJ, VanWormer JJ, Crain AL, Boucher JL, Histon T, Caplan W, et al. Weight-Loss Outcomes: A Systematic Review and Meta-Analysis of Weight-Loss Clinical Trials with a Minimum 1-Year Follow-Up. Journal of the American Dietetic Association 2007;107:1755-67.

14. Metsios GS, Stavropoulos-Kalinoglou A, Veldhuijzen van Zanten JJ, Treharne GJ, Panoulas VF, Douglas KM, et al. Rheumatoid arthritis, cardiovascular disease and physical exercise: a systematic review. Rheumatology (Oxford) 2008;47:239-48.

15. Gaesser GA. Exercise for prevention and treatment of cardiovascular disease, type 2 diabetes, and metabolic syndrome. Curr Diab Rep 2007;7:14-9. 


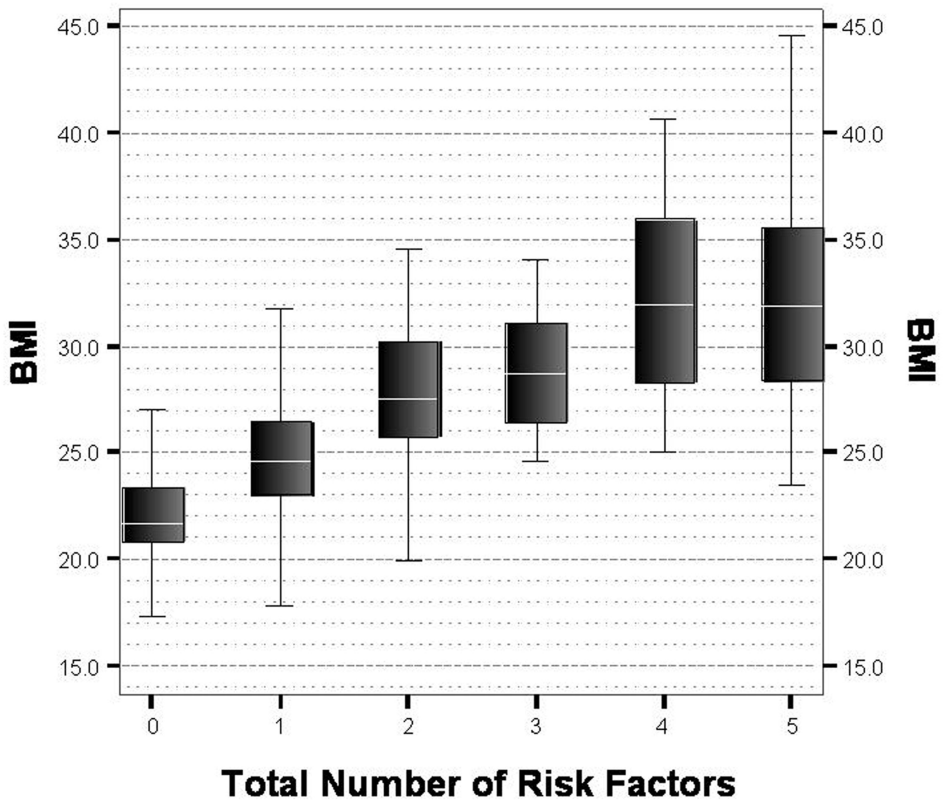




\section{Hypertension}

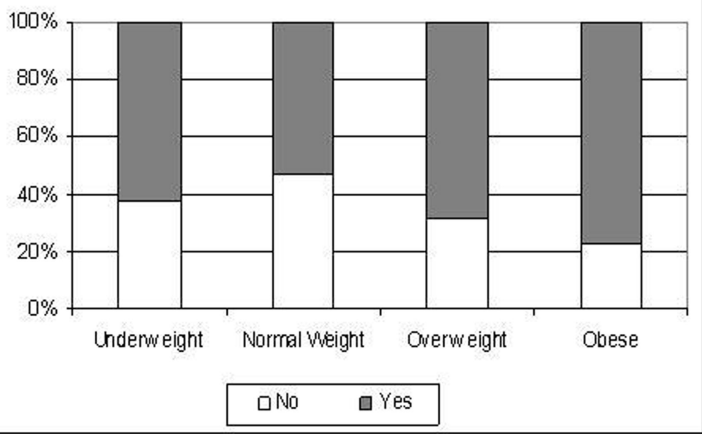

\section{Insulin resistance}

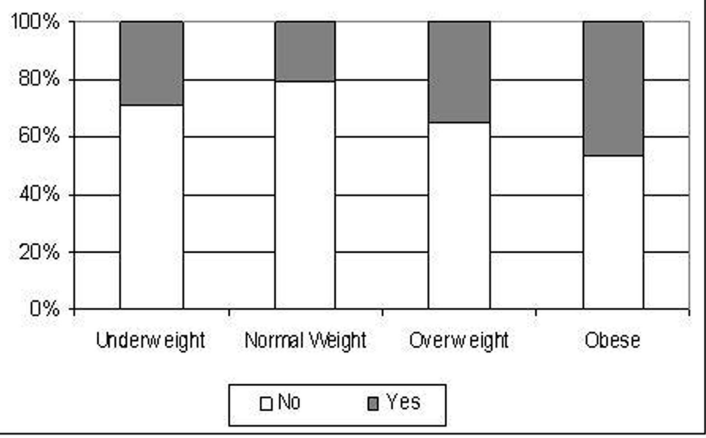

Dyslipidaemia

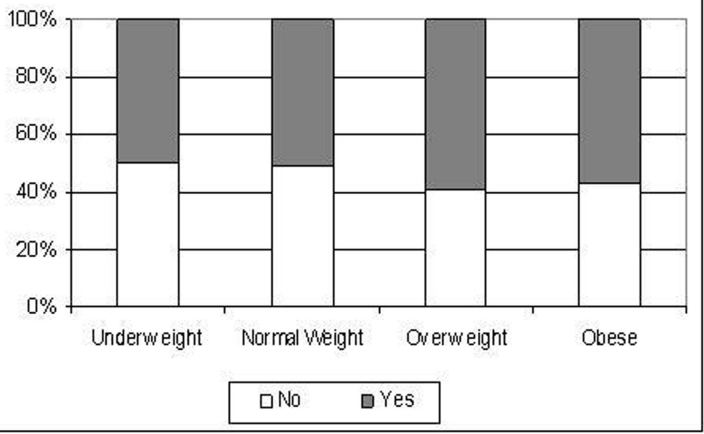

Metabolic Syndrome

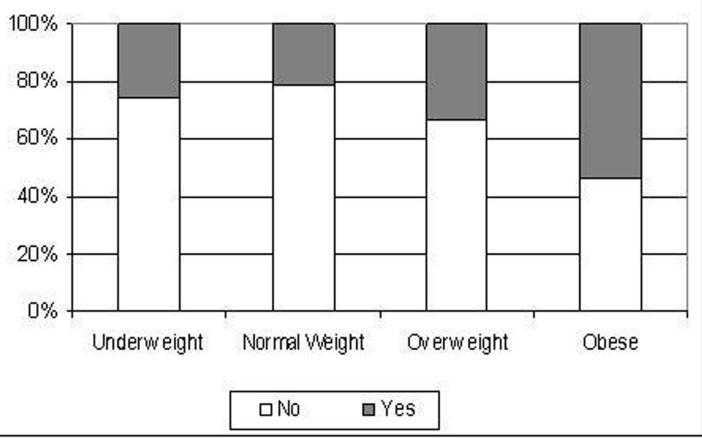

